\title{
Monitoring the Decline of Persian oAK in Iran USING REMOTE SENSING - CASE STUDY OF BASHT FOREST
}

\author{
Sahar Haydari naserabad ${ }^{1}$, Alireza Salehi ${ }^{2}$, Zahra Azizi $^{3}$, MarjanFiroozy Nejad ${ }^{4}$ \\ 1. Natural Resources-Forestry, Forestry Department, University of Yasouj. \\ 2. Department of Forestry, University of Yasouj. \\ 3. Department of RS-GIS, Faculty of Environment and \\ Energy, Science and Research Branch, Islamic Azad University, Tehran, Iran. \\ 4. Range and watershed management Department, Ramin Agricultural and Natural Resources University of \\ Khuzestan.
}

(Received 3 May 2017 - Accepted 11 January 2018)

\begin{abstract}
Haydari Naserabad, S. Salehi, A. Azizi, Z. and Firoozy Nejad. M. 2018. Monitoring the Decline of Persian oak in Iran using Remote Sensing - Case study of Basht forest. Lebanese Science Journal, 19(1): 67-73.

Oak forest decline is a complex problem that it has started for a long time ago in the world. This problem is widely spread because of lacking of efficient and reliable facilities for monitoring these forests. In this research, the pattern of spatial-temporal distribution and decline of Iranian Oak stands in the Basht forest was monitored using remote sensing. The area of study is located in the provinces of Kohgilouyeh and Boyer Ahmad in Iran. After selecting the study area, forest visits were carried out and samples of dead trees were collected. Based on the oak crown decline attack, the forest was divided into four categories: low (crown dieback 20-0 percent), medium (between 40-20\% of crown dieback), high (between 60-40\%) and severe (more than 60\% crown dieback). The geographical locations of the harvested trees were recorded using global positioning system (GPS). In order to determine the most appropriate vegetation index, root mean square error (RMSE) for 12 vegetation indices were calculated from Landsat 8 images. The results of this study proved that ratio vegetation index (RVI) indicator with the lowest RMSE was an appropriate tool for assessing the status of the Iranian Oak forests. Finally, in order to study temporal changes of the Oak forests, dieback canopy variance and RVI for 6 years (1987, 2000, 2003, 2009, 2013 and 2014) were computed from different Landsat images. The computed indices indicated that crown freshness witnessed significant and continuous decrease.
\end{abstract}

Keywords: Oak forests, GIS, landsat image, vegetation indices.

\section{INTRODUCTION}

The degradation of oak forest is a result of the interaction between biotic and abiotic factors which leads to trees dieback and gradual loss of the forest cover (Hosseini, 2001). Forest cover has been degrading very fast, with tree color changes from green to brown (Mirabolfathy, 2014; Fan et al, 2012). Several factors such as low rate rainfall, high temperatures, drought duration as well as the dust emission and human interference, could all contribute to this dieback (Hamzehpour et al., 2011). The incidence of this dieback in addition to the spread of pests and diseases are primary causes that threaten the oak forest of Zagros today (Hosseini, 2001). Several studies by local experts reported dieback spread and mortality of oak trees. In 2008, in Ilam and Lorestan provinces of Iran, fast degradation of Zagros oak trees was observed (Mirabolfathy, 2014). The use of remote sensing technology such as imagery of Landsatt, detect and map damaged and dead trees, is a useful tool to monitor forest health because of its lower cost, larger coverage, ease of processing and providing data on time (Mäkelä and Pekkarinen, 2004). Wang et al. (2004), reported that for appropriate forest management systems practitioners need to access real-time information on the quality of the trees to timely develop control measures. The use of remote sensing technology to recognize the spectral data and identify the spatial

http://dx.doi.org/10.22453/LSJ-019.1.067-073 National Council for Scientific Research - Lebanon 2018@ lsj.cnrs.edu.lb/vol-19-no-1-2018/ 
distribution of damaged and healthy stands is thus extremely important (Zakeri and Falahshamsi, 2014). Bozorgmehr et al (2014), investigated ash dieback in the Chahar Tagh's forest of Iran and compared ETM satellite imagery and 17 vegetation indexes. The results of their study showed that the following indicators perpendicular vegetation index 1 (PVI1), perpendicular vegetation index 3 (PVI3), weighted difference vegetation index (WDVI), transformed soil adjusted vegetation index (TSAVI), had the following correlation values $0 / 15,0 / 21,0 / 21$ and 0/22, respectively, and were the most relevant to the tree crown dieback.

In recent years, the forest cover of south Zagros, especially persian oak, has been degrading due to unforeseen reasons (Zakeri and Falah Shamsi, 2014). The flexibility of some remote sensing satellites with respect to the temporal resolution makes it possible to recognize the spatial distribution patterns of Oak and map its decline in dead stands. This research aimed to determine the temporal degradation of the oak forest and the distribution of Iranian oak in the last three decades using remote sensing.

\section{MATERIALS AND METHODS}

\section{Study Area}

This study was carried out in AbkhizBasht forest at southwest Kohgiloyeh and Boyerahmad in Iran. Major forest cover is broad leaf trees, especially Iranian oak. The study area is located between longitude $30^{\circ} 17^{\prime} 19^{\prime \prime}$ to $30^{\circ}$ $23^{\prime} 54^{\prime \prime} \mathrm{N}$ and latitude $51^{\circ} 7^{\prime} 50^{\prime \prime}$ to $51^{\circ} 13^{\prime} 46^{\prime \prime} \mathrm{E}$, which covers around 150 hectares of land area (Fig. 1). The slope gradient ranged between 7 and $70 \%$ and the elevation varied from 600 to 1500 meters. The slope direction is south and west, and based on De Martonne index the climate area is semiarid (Ghasemi Far and Naserpur, 2015).

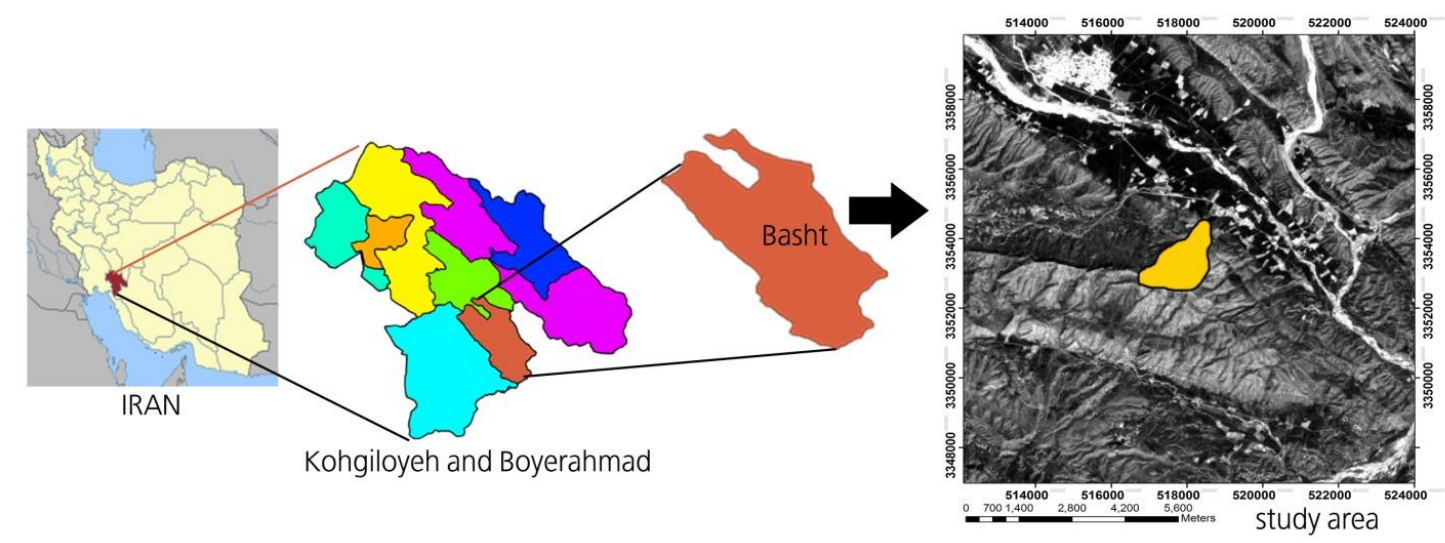

Figure 1. The location of study area in Kohgiloyeh and Boyerahmadin the province of Iran.

\section{Data and Methodology}

In this study, Landsat 7TM and ETM images, (path 163 and row 39) for the $6^{\text {th }}$ of April 1987, 2000, 2003, 2004, 2006 and 2009, and Landsat 8, for the years 2013 and 2014 were used. The software ENVI 4.8, Arc GIS 10, EXCEL and SPSS were also used.

Radiometric corrections were calculated before vegetation indices, the radiometric correction of OLI images were performed by using Equation 1, image metadata files and ENVI 4.8 software (Feyzizadeh et al, 2016).

$$
\text { Equation 1: } \quad \mathrm{L}_{\lambda}=\mathrm{M}_{\mathrm{L}} \mathrm{Q}_{\mathrm{Cal}}+\mathrm{AL}
$$

$L_{\lambda}=$ Spectral radiance upper atmosphere (Watts $\left./ \mathrm{m}^{2 *} \mathrm{Srad}^{*} \mu \mathrm{m}\right)$

$\mathrm{M}_{\mathrm{L}}$ and $\mathrm{A}_{\mathrm{L}}=$ Conversion ratio

$\mathrm{Q}_{\text {Cal }}=$ Satellite image 
When red and near-infrared bands data were compared to other spectra showed a higher correlation with the oak decline. In order to evaluate the Oak crown dieback, the vegetation indices based on the combination of red and near-infrared bands were used. To verify the period of oak stands decline, 12 vegetation indices were calculated (Table 1) using Landsat 8 images (Sepehri, 2002; AlaviPanah and Ehsani, 2003; Jabbari et al., 2011).

Table1. Vegetation indices formulas used to identify the dieback of oak stands in Iran.

\begin{tabular}{|c|c|c|}
\hline Index & Formula & References \\
\hline \multirow{2}{*}{ NDVI } & $N I R-R E D$ & \multirow{2}{*}{ Rouse et al 1996} \\
\hline & $\overline{N I R+R E D}$ & \\
\hline DVI & $N I R-R E D$ & Tucker et al 1979 \\
\hline RDVI & $\sqrt{N D V I \times D V I}$ & Breon\& Roujean,1995 \\
\hline CTVI & $\frac{N D V I+0.5}{A B S(N D V I+0.5)}+\sqrt{A B S(N D V I+0.5)}$ & Eastman, 1995 \\
\hline TTVI & $\sqrt{A B S(D V I \times 0.5)}$ & Eastman, 1995 \\
\hline \multirow{2}{*}{ RVI } & $R E D$ & \multirow{2}{*}{ Mather,1999 } \\
\hline & $\overline{N I R}$ & \\
\hline \multirow{2}{*}{ NRVI } & $R V I-1$ & \multirow{2}{*}{ Eastman, 1995} \\
\hline & $\overline{R V I+1}$ & \\
\hline SR & $\frac{N I R}{D \Gamma D}$ & Birth \& McVey, 1968 \\
\hline \multirow{2}{*}{ SAVI } & $\frac{R E D}{(1+L)(N I R-R E D)}$ & \multirow{2}{*}{ Huete, 1988} \\
\hline & $N I R+R E D+L$ & \\
\hline \multirow{2}{*}{ SAVI1 } & NIR & \multirow[b]{2}{*}{ Major et al,1990 } \\
\hline & $\overline{R E D+\frac{b}{a}}$ & \\
\hline \multirow{2}{*}{ OSAVI } & $(1+L)(N I R-R E D)$ & \multirow{2}{*}{ Rondeaux et al,1996 } \\
\hline & $\frac{N I R+R E D+L}{}$ & \\
\hline MSAVI2 & $N I R+0.5-\sqrt{(N I R+0.5)^{2}}-2(N I R-R E D)$ & Qi et al, 1994 \\
\hline
\end{tabular}

The Iranian oak declined between the years of 1987 and 2014 as proven by calculating 12 indicators (normalized difference vegetation index (NDVI), divergence vegetation index (DVI), ratio vegetation index (RDVI), corrected transformed vegetation index (CTVI), Thiam's transformed vegetation index (TTVI), ratio vegetation index $(R V I)$, normalized ratio vegetation index (NRVI), simple ratio (SR), soil -adjusted vegetation index (SAVI), soil adjusted vegetation index I (SAVII), soil -adjusted vegetation index (OSAVI), modified soil adjusted vegetation index (MSAVI2)) using Landsat satellite images and the results were verified using field data. The verification showed that RVI had the lowest root mean square error $(\mathrm{RMSE}=0.001)$ (Table 2). Accordingly, this index was used to investigate the causes of oak degradation for all years $(1987,2000,2003,2009,2013$ and 2014) and categorized in 4 classes of \% decline of tree crowns $(0-20 \%, 20-40 \%, 40-60 \%$ and more than $60 \%)$. To compare the mean decline level $(\%)$ for 4 classes, 6 different years were used in the analysis of variance with repeated measures (Susan et al., 2009). The assumptions considered for this test included data normality and homogeneity of covariance. To normalize the data, the Kolmogorov-Smirnov test was used (Hosseini, 2001), and to investigate the homogeneity of covariance, the Mauchly's sphericity test was applied. It is a statistical test used to validate repeated measures analysis of variance (ANOVA). Based on the results of F-test, LSD test was used. 
Table 2. A comparison of bias and RMSE of vegetation indices of OLI images.

\begin{tabular}{|l|l|l|}
\hline \multicolumn{1}{|c|}{ Vegetation Index } & \multicolumn{1}{c|}{ bias } & \multicolumn{1}{c|}{ RMSE } \\
\hline TTVI & $0 / 24$ & 0.02 \\
SR & $-1 / 25$ & 10.49 \\
SAVI2 & $-1 / 00$ & 4.37 \\
SAVI & $0 / 01$ & 0.00 \\
RDVI & $0 / 02$ & 0.00 \\
OSAVI & $-0 / 02$ & 0.00 \\
RVI & $-0 / 00$ & 0.00 \\
NRVI & $0 / 40$ & 0.14 \\
NDVI & $-0 / 07$ & 0.00 \\
MSAVI2 & $0 / 02$ & 0.00 \\
DVI & $0 / 06$ & 0.00 \\
\hline
\end{tabular}

The results of Mauchly's sphericity test for different dieback classes (0-20\%, 20-40\%, 40-60\% and more than $60 \%$ ). showed that all classes were significant at $5 \%$ level (Table 3). This confirmed the assumption of homogeneity of variances which can be used in the analysis of variance with duplicate measurements.

Table 3. Results Mauchly's sphericity test of different dieback classes on the homogeneity of covariance.

\begin{tabular}{|l|l|l|l|l|}
\hline $\begin{array}{l}\text { Decline classes } \\
(\%)\end{array}$ & $\begin{array}{l}\text { The effects of intra- } \\
\text { group }\end{array}$ & Significance & $\begin{array}{l}\text { Mauchly's test of } \\
\text { sphericity }\end{array}$ & Chi-square \\
\hline $0-20$ & factor & $0 / 09$ & $0 / 01$ & $27 / 74$ \\
$20-40$ & factor & $0 / 06$ & $0 / 00$ & $16 / 84$ \\
$40-60$ & factor & $0 / 10$ & $0 / 05$ & $26 / 34$ \\
$>60$ & factor & $0 / 30$ & $0 / 55$ & $58 / 27$ \\
\hline
\end{tabular}

The results of analysis of variance between decline classes in different years, revealed that there was a significant difference at the alpha level (significance level) of 5\%. This difference was observed in classes of 0-20\%, 20-40\% percent in 1987-2009, and classes of 40-60\% in 1987-2013 and more than 60\% in 1987- 2003, $1987-2009,1987-$ 2013 and 1987-2014 years (Table 4). Crown freshness has decreased significantly between the years of 1987 and 2014. Accordingly, the average crown freshness in 1987 was 0/88, whereas it reached 0/362 in 2014 (Fig. 2). 
Table 4. A comparison of the average LSD decline in different time periods.

\begin{tabular}{|c|c|c|c|c|c|c|}
\hline Classes decline & \multicolumn{2}{|c|}{$\begin{array}{c}\text { Different periods time } \\
1987-2014\end{array}$} & F-ratio & sig & $\begin{array}{l}\text { Standard } \\
\text { Error }\end{array}$ & $\begin{array}{c}\text { Mean difference of } \\
\text { the Year }\end{array}$ \\
\hline \multirow{5}{*}{$0-20$} & 2000 & \multirow[t]{5}{*}{1987} & \multirow{5}{*}{$22 / 87$} & $0 / 54$ & $0 / 02$ & $0 / 01^{n s}$ \\
\hline & 2003 & & & $0 / 17$ & $0 / 01$ & $0 / 02^{n s}$ \\
\hline & 2009 & & & $0 / 00$ & $0 / 01$ & $0 / 10^{* *}$ \\
\hline & 2013 & & & $0 / 00$ & $0 / 01$ & $0 / 10^{* *}$ \\
\hline & 2014 & & & $0 / 00$ & $0 / 01$ & $0 / 40^{* *}$ \\
\hline \multirow[t]{5}{*}{$20-40$} & 2000 & \multirow[t]{5}{*}{1987} & \multirow{5}{*}{$26 / 66$} & $0 / 20$ & $0 / 00$ & $0 / 04^{n s}$ \\
\hline & 2003 & & & $0 / 19$ & $0 / 01$ & $0 / 17^{n s}$ \\
\hline & 2009 & & & $0 / 00$ & $0 / 00$ & $0 / 22^{* *}$ \\
\hline & 2013 & & & $0 / 00$ & $0 / 00$ & $0 / 53$ \\
\hline & 2014 & & & $0 / 00$ & $0 / 00$ & $0 / 53^{* *}$ \\
\hline \multirow[t]{5}{*}{$40-60$} & 2000 & \multirow[t]{5}{*}{1987} & \multirow{5}{*}{$24 / 38$} & $0 / 10$ & $0 / 01$ & $0 / 19$ \\
\hline & 2003 & & & $0 / 00$ & $0 / 01$ & $0 / 19^{* *}$ \\
\hline & 2009 & & & $0 / 00$ & $0 / 01$ & $0 / 22^{* *}$ \\
\hline & 2013 & & & $0 / 00$ & $0 / 02$ & $0 / 23$ \\
\hline & 2014 & & & $0 / 00$ & $0 / 01$ & $00 / 54^{* *}$ \\
\hline \multirow[t]{5}{*}{$>60$} & 2000 & \multirow[t]{5}{*}{1987} & \multirow{5}{*}{$14 / 39$} & $0 / 07$ & $0 / 02$ & $0 / 07^{n s}$ \\
\hline & 2003 & & & $0 / 00$ & $0 / 03$ & $00 / 14^{* *}$ \\
\hline & 2009 & & & $0 / 00$ & $0 / 02$ & $0 / 21^{* *}$ \\
\hline & 2013 & & & $0 / 00$ & $0 / 03$ & $0 / 31^{* *}$ \\
\hline & 2014 & & & $0 / 00$ & $0 / 02$ & $0 / 56^{* *}$ \\
\hline
\end{tabular}

$* *=$ Significant at $1 \%, n s=$ not significant.

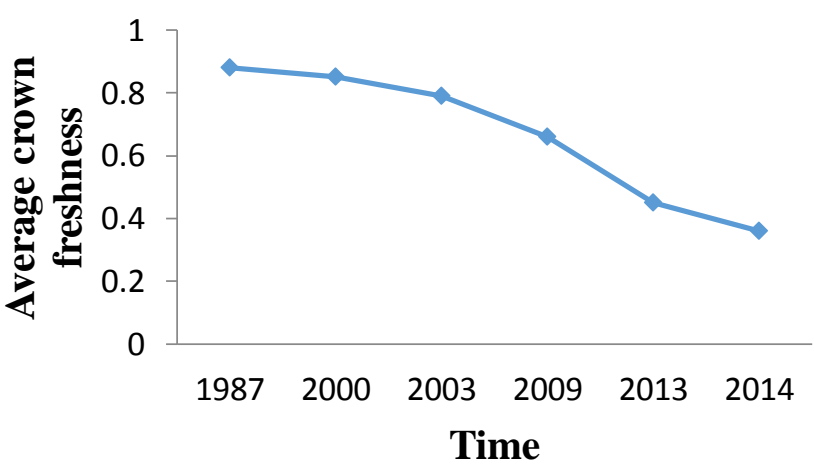

Figure 2. The results of average crown freshness trend (1987-2014).

\section{DISCUSSION}

To monitor and evaluate the current status of the oak forests in Iran, a number of vegetation indices were calculated for different Landsat images which covered different time periods. Based on the validation of the indices with field data, RVI index showed the lowest RMSE compared to the other indices.

RVI index helped in reducing the effect of soil cover on the forest cover (Mather, 1999; Smith et al., 1990; Rondeaux et al. 1996). Compared average of the decline of Iranian oak in four classes $(0-20,20-40,40-60$ and $>60 \%)$ indicated a decrease of the crown freshness in the six time periods $(1987,2000,2003,2009,2013$ and 2014). The 
decreased average in crown freshness in all classes demonstrated a continued decline of Iranian oak.. In other words, oak crown decline in 2014 was more noticable than in other time periods assessed in this study, and agrees with the findings of Susan et al. (2009) and Wang et al. (2008).

\section{ACKNOWLEDGEMENTS}

The Authors are thankful to the Iranian Space Agency for satellite images and all those who helped us in the field work and all colleagues for useful suggestions and comments including manuscript writing.

\section{REFERENCES}

AlaviPanah, S., A., Ehsani, 2003,Evaluation of desertification and changes in land cover data using multi-temporal and multi-spectral satellite, Desert Journal, 1(9): 271-259.

Bozorgmehr, A., A., Abrahami and M, Abbasid. 2014. Compared vegetation indices to estimate forest dieback Ash wide for storage. First National Conference for oak forests.

Eastman, J. R. 1995. Idrisi for Windows: user's guide, version 1.0. Clarks Labs for Cartographic Technology and Geographic analysis, Clarks University, Worchester,Massachusetts.

Fan, Z., Fan, X., Crosby, M. K., Moser, W. K., He, H., Spetich, M. A., and Shifley, S. R. 2012. Spatio-temporal trends of oak decline and mortality under periodic regional drought in the Ozark Highlands of Arkansas and Missouri. Forests, 3: 614-631.

Feyzizadeh, Bakhtiyar, Didehban Khalil and Gholamniya Khalil. 2016. Land surface temperature estimation using Landsat 8 satellite imagery and a separate window algorithm (Case study: Mahabad area), Scientific Research Quarterly of Geographical Data (SEPEHR), 25: 171-181.

Ghasemi Far Elham and Naserpur Somayeh. 2015. Climatic zoning of the Zagros region, Sepehr Geographic Information Journal, 23:54-60.

Hamzehpour, M., Kia-daliri, H. and Bordbar, K. 2011. Preliminary study of manna oak (QuercusbrantiiLindl.) tree decline in Dashte-Barm of Kazeroon, Fars province, Iranian Journal of Forest and Poplar Research, 19:352363.

Hosseini, A. 2001. The evolution of wood-eating beetle infestation and its relationship with habitat conditions in forests of Iranian oak (Quercusbrantii) in Ilam province. Research Journal for the protection and conservation of forests and rangelands of Iran, 66(1): 9.

Huete, A. R. 1988. A Soil_adjusted vegetation index (SAVI). Remote Sensing environment, 25: 295-309.

Jabbari, Q, c, khaje Din, Q, Sultan, R, Jafari. 2011, determine vegetation land using GIS and RS (Case study: Semirom), National Geomatics Conference.

Major, D. J., Baret, F., and Guyot, G. 1990. A ratio vegetation index adjusted for soil brightness. International Journal of Remote Sensing, 11: 727-740.

Mäkelä, H., Pekkarinen, A. 2004. Estimation of forest stand volumes by Landsat TM imagery and stand-level fieldinventory data. Forest Ecology and Management, 196:245-255.

Mather P.M. 1999. Computer processing of remotely sensed images, 2nd Edition. John Wiley \& Sons.

Mirabolfathy, M. 2014. Outbreak of charcoal disease on Quercus spp. and Zelkova Carpinifolia trees in forests of Zagros and Alborz mountain in Iran. Plant Disease, 49(2): 257-263.

Rondeaux, G., Steven, M., and F. Baret. 1996. Optimization of soil-adjustedvegetation indices. Remote Sensing of Environment, 55:95-107.

Rouse J.W., Hass. R.H., Schell, J. A. Deering, D. W. 1973. Monitoring Vegetation systems in the Great Plains with ERTS, in Third Earth Resources Technology Satellite-1 Symposium, Washington DC: NASA, pp. 309-317.

SEPEHRI, S., M. Mataq. 2002. Using vegetation indices for estimation of canopy cover percentage of rangeland vegetation (in aprotected area of Jhan-Nma,Gorgan). Iranian Journal of Natural Resources, 55(2):271-259.

Smith. M.O., S.L. Using, J.B. Adams, and A.R. Gillespie. 1990. Vegetation in Deserts: I. A Regional Measure of Abundance from Multispectral Image. Remote Sensing of Environment, 31: 1-26.

Susan, G. W., William, F., Henrique, E. M., Phillip, M., Expedito, R. G., and Richard, C. 2009. Long-term variation in Amazon forest dynamics. Journal of Vegetation Science (International Association for Vegetation Science), 20: 323-333.

Tucker, C. J. 1979. Red and photographic infrared linear combinations for monitoring vegetation. Remote sensing of Environment, 8(2): 127-150. 
Wang, C., He, H. S., and Kabrick, J. M. 2008. A remote sensing-assisted risk rating study to predict oak decline and recovery in the Missouri Ozark Highlands, USA. GIScience \& Remote Sensing, 45(4):406-425.

Zakeri Anaraki, Q., and R. Fallah Shamsi. 2014. An Investigation on Persian oak (Quercus brantii Lind) single tree defoliation mapping, using Rapideye and Aster-L1B Satellite Imageries. Iranian Journal of Forest, 5(4): pages?? 